\title{
Avaliação da propaganda de medicamentos veiculada em emissoras de rádio
}

\author{
Evaluation of medication advertising broadcast on radio stations
}

Almária M ariz Batista ${ }^{1}$

M aria Cleide Ribeiro Dantas de Carvalho ${ }^{1}$

${ }^{1}$ Laboratório de

M onitoração dePropaganda deProdutos Sujeitosà Vigilância Sanitária, UniversidadeFederal do Rio Grande do N orte(UFRN) RuaAbdon N unes 871/602. 59014-540 Natal RN. cleidecarvalho@hotmail.com
Abstract The scope of this paper was to evaluate advertising for medication broadcast on radio stations in N atal, State of Rio Grande do N orte, Brazil, from A pril to September 2008 and from April to September 2010. The advertising was recorded and transcribed in order to conduct legal analysis and content analysis based on the precepts of Laurence Bardin. Both the advertising recorded during the first stage (regulated by RDC 102/00) and the second stage (regulated by RDC 96/08) contained someform of legal violation. Content analysis detected practically the same violations in both stages, namely the lack of information re garding adverse effects of the medication, appeal to consumption, exaggeration of efficiency/effectiveness and abusive exploitation of illness. De spite the inclusion of more modern and restrictive legislation, radio advertising continues to violate the law blatantly, committing abuse and disrespecting the population's entitlement to good health. The study reveals the need for medication advertising to be dealt with in a broader context, in other words to be treated as a public health concern. It must take into consideration the socio-historical scenario in which it evolved, since thelegislation alone is insufficient to combat abuse committed to the detriment of public health.

Key words Advertising, Medication, Radio, Regulation, Rational use
Resumo 0 objetivo deste estudo foi avaliar propagandas de medicamentos veiculadas em emissoras de rádio em Natal (RN), Brasil, nos períodos de abril a setembro de 2008 e abril a setembro de 2010. As propagandas foram captadas, gravadase transcritas para se efetuar uma análiselegal euma de conteúdo baseada nos preceitos de Laurence Bardin. Tanto as captadas no primeiro período (sob égide da RDC 102/00), quanto às do segundo (sob égide da RDC 96/08), apresentaram algum tipo deinfração legal. A análise de conteúdo detectou, em ambos os períodos, praticamente os mesmos vícios como ausência de informações negativas sobre o medicamento, apelo ao consumo, exaltação da eficiência/eficácia e exploração abusiva de enfermidades. Apesar da mudança para uma legislação mais moderna e mais restritiva, as propagandas de medicamentos, no rádio, continuam a infringir frontalmente a legislação, cometendo abu sos edesrespeitando o direito à saúde da população. 0 estudo aponta para a necessi dade do tema propaganda de medicamentos ser tratado em um contexto maisamplo, ou seja, discutido como questão de saúde pública, considerando-se o cenário histórico-social em que se desenvolveu, uma vez quesó a legislação não ésuficiente para coibir abusos praticados em detrimento da saúde pública.

Palavras-chave Propaganda, M edicamento, Rádio, Regulação, U so Racional 
Introdução

No Brasil, o mercado farmacêutico faturou, em 2008, cerca de 13,4 bilhões de dólares, ocupando a $10^{2}$ posição mundial ${ }^{1}$. Em 2007, cerca de $R \$ 863$ milhões foram gastos com publicidade no setor dos medicamentos isentos de prescrição (MIP), ficando dividido entreos seguintes veículos: 75\% para televisão, 14\% para rádio, $5 \%$ para TV por assinatura, $5 \%$ em revistas e $1 \%$ para jornais.

No Brasil cerca de $90 \%$ dos domicílios dispõem de rádio ${ }^{2}$, o qual se constitui num veículo de alta penetração nas massas populares e cuja audiência predomina nas classes sociais C e D constituídas, na maioria, por pessoas com escolaridade incipiente, não dispondo de alguns conhecimentos para efetuar uma análise crítica das propagandas demedicamentos, tornando-se, por conseguinte, presa fácil da publicidade enganosa.

A atual legislação brasileira permite que ape nas a propaganda de MIP seja feita diretamente ao consumidor, a qual pode ser veiculada em qual quer meio de comunicação. Dentreos veículos de comunicação, o rádio tem-se constituído numa importante ferramenta de divulgação de anúncios de medicamentos, sobressaindo-se como extraordinário instrumento para o convencimento do consumidor, incrementando seu consumo e a automedicação.

A propaganda, ao divulgar medicamentos como produto de consumo, tende, entre outras coisas, a induzir a automedicação, a agravar doenças ou sintomas, incentivar a aquisição de produtos ineficazes ou inadequados ea ampliar gastos do Sistema de Saúde, inclusive, no que diz respeito ao tratamento de intoxicação medicamentosa, que ocupou, em 2007, primeiro lugar no ranking de intoxicações nos centros de controle de toxicologia e farmacovigilância do Bra$\mathrm{sil}^{3}$, devendo, portanto, ser tratada em um contexto mais amplo, como questão de saúde pública, considerando-seo cenário histórico-social em que se desenvolveu.

A realidadelatino-americana exige perspectiva de pensamento quecontemplenecessidade de proteção dos vulneráveis, uma proposta quejustifique ações concretas do Estado. N este sentido, a "bioética de intervenção" parte do pressuposto deque decisões e políticas sanitárias públicas eticamente adequadas são aquelas que atendem ao maior número de pessoas, pelo maior espaço de tempo possível equeresultem nas melhores consequências coletivas ${ }^{4,5}$. Tal controle é eticamente defensável uma vez que, em questões básicas como saúde pública, o Estado devetomar a fren- te e intervir no compromisso de proteger a população contra qualquer possibilidade de ação quevenha causar-Ihe dano, ou seja, intervir frente ao risco sanitário iminente que podedecorrer do consumo descontrolado de medicamentos ${ }^{6}$.

Outros trabal hos que avaliaram a propaganda de medicamentos isentos de prescrição, veiculadas em diversas mídias, obtiveram resultados bastante preocupantes, principalmente, em relação à omissão de dados importantes como contraindicações e reações adversas, além de induzirem ao seu uso indiscriminado ${ }^{7-9}$.

Poucos estudos têm avaliado, especificamente, propagandas de medicamentos veiculadas no rádio. No Brasil, o trabalho de $\mathrm{H}$ eineck et al..$^{9}$ é pioneiro e exclusivo, demonstrando dados bastante contundentes em relação às infrações cometidas frente às normas legais e ao estímulo ao uso irracional de medicamentos.

Nesse contexto, o presente trabalho objetivou avaliar a conformidade das propagandas de medicamentos veiculadas nas princi pais emissoras de rádio da cidade de $N$ atal (RN) durante a vigência da RDC $n^{\circ} 102 / 00^{10}$ bem como o impacto da RDC $n^{\circ} 96 / 08^{11}$ sobre as peças publicitárias veiculadas após sua vigência.

\section{Metodologia}

As propagandas foram obtidas através da gravação da programação veiculada em 09 emissoras de rádio da cidade de $N$ atal (RN), nos períodos de abril a setembro de 2008 e abril a setembro de 2010, durante 2 horas diárias, conside rando o período de 6 às 18 horas, adotando-se este mesmo padrão de captação das peças publicitárias para os dois períodos (2008/2010). As gravações foram realizadas em aparelho M P3 e, posteriormente, transcritas ipsis literis. Para a análise, cada propaganda diferente foi conside rada como uma peça publicitária independente. Foram desprezadas as propagandas com o mesmo texto, veiculadas em horários diferentes.

A análise legal foi baseada na RDC $n^{\circ} 102 / 00^{10}$ para as peças publicitárias captadas no período de abril a setembro de 2008 e na RDC n⿳0 $96 / 08^{11}$ para as captadas no período de abril a setembro de2010.

Realizou-se também análise de conteúdo do texto das peças publicitárias através da técnica de Análise de Conteúdo preconizada por Bardin ${ }^{12}$ Para tal, foram estabelecidas as seguintes categorias: indicação terapêutica, acesso ao produto, apelo ao consumo, eficiência/eficácia, exploração 
abusiva de enfermidade, alegria, produto natural, aspectos negativos do produto.

A classificação dos medicamentos segundo a classe terapêutica baseou-se no Dicionário de Substâncias Farmacêuticas Comerciais ${ }^{13}$. Os produtos com mais de um princípio ativo foram enquadrados na categoria terapêutica do princípio ativo principal.

A análise estatística dos dados foi efetuada com o auxílio do Programa SPSS versão 9.0.

\section{Resultados ediscussão}

Foram captadas 14 peças publicitárias diferentes entre si e correspondiam a 11 M IP anunciados em emissoras de rádio da cidade de $\mathrm{N}$ atal (RN), como demonstra a Tabela 1.

A maioria dos medicamentos anunciados pertencia à classe terapêutica analgésicos/antiinflamatórios, o que corrobora dados de estudos realizados em Goiás, M inas Gerais e Rio de Janeiro ${ }^{14,15}$. N os 12 meses, contados de agosto de 2007 a julho de 2008, o segmento de M IP movimentou, no Brasil, cerca de R \$ 7,2 bilhões, o equivalentea $28,5 \%$ do mercado farmacêutico ${ }^{16}$. Deste total, os analgésicos para adultos correspondiam a $12,6 \%$, ou seja, R $\$ 910$ milhões $^{17}$. D esta forma, a dor movimenta uma indústria de milhões de dólares anualmente.

Os grupos farmacológi cos mais utilizados na automedicação são analgésicos e antitérmicos ${ }^{18}$. Além disso, estão disponíveis fora de estabelecimentos farmacêuticos como bares, armazéns e mercearias, contrariando disposições legais, o que facilita muito sua aquisição ${ }^{19,20}$.

A análise legal das propagandas veiculadas nos dois períodos demonstrou que todas as pe- ças publicitárias apresentavam al gum tipo de infração à legislação.

Dados como esses também foram encontrados em outros trabalhos que avaliaram a qualidade das propagandas de medicamentos como a análise de peças publicitárias veiculadas em emissoras de rádio do Rio Grande do Sul, em que foi constatado que nenhuma delas apresentava de clarações quanto a contraindicações e cuidados/ advertências ${ }^{9}$ e a avaliação de peças publicitárias veiculadas em Curitiba (PR), em que também foi verificado que $100 \%$ das propagandas veiculadas em rádio apresentavam alguma infração $0^{21}$.

Os resultados da análise legal estão demonstrados nas Tabelas 2 e 3, os quais superaram percentuais observados em outras análises de peças publicitárias de M IP como as veiculadas em São Paulo (SP), em que verificaram que $49,4 \%$ omitiam contraindicação principal, 44,2\% não apresentavam $n$ - de registro, $27,3 \%$ induziam ao uso indiscriminado e 17,8\% associavam uso do medicamento a desempenho físico/intelectual/emocional/sexual e/ou beleza ${ }^{8}$. Além disto, foi observada a associação do uso do medicamento ao desempenho físico/mental/intelectual e/ou beleza (32,43\%), omissão de no de registro, princípios ativos e nome comercial $(21,28 \%)$, indução a uso indiscriminado $(17,23 \%)$ e omissão da advertência obrigatória $(12,16 \%)^{21}$.

Como a monitoração da propaganda veiculada em rádio é bastante trabalhosa, exigindo dedicação e tempo disponível, fato que dificulta sobremaneira sua fiscalização pelos órgãos competentes, talvez isto justifique o status quo da qualidade da propaganda veiculada neste tipo de mídia, queseconstitui num acintoso desrespeito à legislação em vigor, como mostrado nas Tabelas 2 e3. Desta forma, este veículo torna-se gran-

\begin{tabular}{|c|c|c|c|c|}
\hline \multicolumn{3}{|c|}{ abril a setembro de 2008} & \multicolumn{2}{|c|}{ abril a setembro de 2010} \\
\hline & $\begin{array}{l}\text { Medicamentos } \\
\text { anunciados }\end{array}$ & $\begin{array}{c}\text { № de propagandas } \\
\text { diferentes por medicamento }\end{array}$ & $\begin{array}{l}\text { Medicamentos } \\
\text { anunciados }\end{array}$ & $\begin{array}{c}\text { № de propagandas } \\
\text { diferentes por medicamento }\end{array}$ \\
\hline 1 & $A$ & 2 & B & 2 \\
\hline 2 & $\mathrm{~B}$ & 1 & $\mathrm{H}$ & 1 \\
\hline 3 & $\mathrm{C}$ & 1 & 1 & 1 \\
\hline 4 & $\mathrm{D}$ & 1 & $J$ & 1 \\
\hline 5 & $\mathrm{E}$ & 1 & $\mathrm{~K}$ & 1 \\
\hline 6 & $\mathrm{~F}$ & 1 & & \\
\hline 7 & G & 1 & & \\
\hline Total & & 8 & & 6 \\
\hline
\end{tabular}


Tabela 2. Análise legal das peças publicitárias veiculadas em emissoras de rádio de Natal (RN), Brasil, no período de abril a setembro de 2008, sob égide da RDC $n^{\circ} 102 / 00^{10}$.

\begin{tabular}{|c|c|c|c|}
\hline \multirow[b]{2}{*}{ Artigo infringido } & \multirow[b]{2}{*}{ Infração } & \multicolumn{2}{|c|}{$\begin{array}{l}\text { Peças publicitárias } \\
\text { em desacordo }\end{array}$} \\
\hline & & $\mathrm{N}$ & $\%$ \\
\hline Art. 30,1 & Não consta a contraindicação principal & 8 & 100 \\
\hline Art. $4 \div$, I & Anuncia medicamento não registrado na Anvisa & 1 & 12,5 \\
\hline Art. $50, b$ & Omite a identidade do fornecedor & 8 & 100 \\
\hline Art. 10,1 & Induz ao uso indiscriminado de medicamento & 8 & 100 \\
\hline Art. $10, \mathrm{VII}$ & Explora enfermidade de forma abusiva & 3 & 37,5 \\
\hline Art. $10, x$ & $\begin{array}{l}\text { Relaciona o uso de medicamento ao desempenho físico, } \\
\text { intelectual, emocional, sexual ou beleza }\end{array}$ & 3 & 37,5 \\
\hline Art. 12, a & $\begin{array}{l}\text { Omite: } \\
\text { no de registro na Anvisa }\end{array}$ & 8 & 100 \\
\hline & princípio ativo (DCB/DCI) & 8 & 100 \\
\hline Art. $12, \mathrm{~b}$ & $\begin{array}{l}\text { Omite a advertência obrigatória "Ao persistirem os } \\
\text { sintomas, o médico deverá ser consultado" }\end{array}$ & 1 & 12,5 \\
\hline
\end{tabular}

Tabela 3. Análise legal das peças publicitárias veiculadas em emissoras de rádio de Natal (RN), Brasil, no período de abril a setembro de 2010, sob égide da RDC $n^{\circ} 96 / 08^{11}$.

\begin{tabular}{|c|c|c|c|}
\hline \multirow{2}{*}{$\begin{array}{c}\text { Artigo } \\
\text { infringido }\end{array}$} & \multirow[b]{2}{*}{ Infração } & \multicolumn{2}{|c|}{$\begin{array}{l}\text { Peças publicitárias } \\
\text { em desacordo }\end{array}$} \\
\hline & & $\mathrm{N}$ & $\%$ \\
\hline Art. $3^{\circ}$ & Anuncia medicamento não registrado na Anvisa & 1 & 16,7 \\
\hline Art. 8, I & $\begin{array}{l}\text { Estimula e/ou induz ao uso indiscriminado de } \\
\text { medicamento }\end{array}$ & 6 & 100 \\
\hline Art. 80, II & Sugere ou estimula diagnóstico & 1 & 16,7 \\
\hline Art. 9o, III / IV & $\begin{array}{l}\text { Utiliza expressões como "seguro", "eficaz", "qualidade", } \\
\text { "absoluta", "excelente", "máxima", "ótima", "perfeita", "total" } \\
\text { sem justificativa sobre a veracidade da informação }\end{array}$ & 2 & 33,3 \\
\hline Art. 14 & $\begin{array}{l}\text { Utiliza designações que possibilitam interpretação falsa, } \\
\text { equívoco, erro e/ou confusão em relação à verdadeira } \\
\text { finalidade do produto }\end{array}$ & 1 & 16,7 \\
\hline Art. 17 & $\begin{array}{l}\text { O mite advertência: "(Nome comercial do medicamento, } \\
\text { no caso dos medicamentos genéricos, a substância ativa) É } \\
\text { um medicamento. Durante seu uso, não dirija veículos ou } \\
\text { opere máquinas, pois sua agilidade e atenção podem estar } \\
\text { prejudicadas", quando couber }\end{array}$ & 1 & 16,7 \\
\hline Art. $22, \mathrm{II}$ & Omite princípio ativo ( $\mathrm{DCB} / \mathrm{DCl} /$ nomenclatura botânica) & 6 & 100 \\
\hline Art. 22, V & Omite indicações & 1 & 16,7 \\
\hline Art. 22,VII & $\begin{array}{l}\text { O mite advertência: "Ao persistirem os sintomas, o médico } \\
\text { deverá ser consultado" }\end{array}$ & 1 & 16,7 \\
\hline Art. 23 & $\begin{array}{l}\text { O mite advertência relacionada à substância ativa do } \\
\text { medicamento, conforme tabela do anexo III ou "(Nome } \\
\text { comercial do medicamento, no caso dos medicamentos } \\
\text { genéricos, a substância ativa) É um medicamento. Seu uso } \\
\text { pode trazer riscos. Procure o médico e o farmacêutico. Leia } \\
\text { a bula" }\end{array}$ & 4 & 66,7 \\
\hline Art. 26, II & $\begin{array}{l}\text { Faz crer que são supérfluos hábitos de vida saudáveis elou } \\
\text { consulta ao médico }\end{array}$ & 1 & 16,7 \\
\hline
\end{tabular}


de aliado da indústria farmacêutica para satisfação de seus propósitos mercadológicos.

A propaganda de M IP realizada no Brasil vai de encontro à atual Política Nacional de M edicamentos, principalmente, no que diz respeito à promoção do seu uso racional, que é o processo que compreende prescrição apropriada, disponibilidade oportuna e preços acessíveis, dispensação em condições adequadas e consumo nas doses indicadas, nos intervalos definidos e no período detempo indicado demedicamentos eficazes, seguros e de qualidade ${ }^{22}$.

Embora todos os medicamentos anunciados apresentem contraindicação, todas as peças publicitárias avaliadas omitiram a principal. A contraindicação é uma informação imprescindível que significa declarar as condições (grupos populacionais e/ou doenças) em quea utilização do medicamento não érecomendada, devendo, portanto, merecer destaque especial. N os anúncios veiculados no rádio, o locutor deveria falar pausadamente, chamando atenção do ouvinte para esta informação, pois sua omissão pode conduzir à má utilização dos medicamentos, pondo em risco a saúde do usuário. Por exemplo, um dos analgésicos mais utilizados pela população, 0 ácido acetilsalicílico, pode provocar sangramento gastrintestinal, além de intensificar o efeito de anticoagulantes orais $s^{23}$.

Na RDC no 102/0010, as contraindicações estão contempladas no inciso I do artigo 30 enquanto na RDC no 96/08 ${ }^{11}$, nos artigos 17 e 23 sob a forma de advertências específicas para determinados princípios ativos. Esta mudança na legislação foi determinada pela grandeincidência de infrações em relação a esteaspecto durante a vigência da RDC no 102/0010, uma vez que chamar a atenção das contraindicações através de uma advertência traria maisimpacto do quesimplesmente citá-las. Apesar deste avanço, as peças publicitárias captadas no 2ำ período infringem de forma significativa a legislação (83,3\%), assim como as captadas no 1 - (100\%), quanto a este aspecto.

A omissão da DCB/DCl ocorreu em todas as peças publicitárias avaliadas. Este item éimprescindível porque o usuário deve ser informado sobrea(s) substância(s) ativa(s) do medicamento, a fim de evitar utilização indevida em casos de intolerância ou alergias. Além disso, sabendo-se qual é o princípio ativo, pode-se escolher aquele com o preço mais razoável.

A exigência do número do registro do medicamento na propaganda veiculada no rádio (art. 12 daRDC $n^{\circ} 102 / 00^{10}$ ) foi abolida na RDC $n^{\circ} 96 /$ $08^{11}$, no entanto, de acordo com o item " $b$ ", do inciso VII, do art. 22 “a emissora de rádio, a partir da venda do espaço promocional, deve ter à disposição do consumidor e da autoridade sanitária, a informação sobre o número de registro [...]". Todas as propagandas captadas no 1o período omitiram o número do registro durante a vei culação das mesmas. $\mathrm{N}$ as do 20 período, nenhuma emissora de rádio soube informar, quando consultada, o número do registro do medicamento anunciado, demonstrando que este item continua sendo ignorado pelos anunciantes de medicamentos no rádio.

A exploração de enfermidade de forma abusiva também foi detectada nas peças publicitárias captadas durante ambos os períodos do estudo, sendo no 1 o período $3(37,5 \%)$ e no 2 o, 1 $(16,7 \%)$, embora a RDC $n^{\circ} 96 / 00^{11}$ em seu artigo 26 , inciso VI conste que é vedado apresentar de forma abusiva, enganosa ou assustadora representações visuais das alterações do corpo humano causadas por doenças ou lesões, nas peças publicitárias captadas no período de abril a setembro de 2010, as expressões 1 ) “... todo malamanhado ..."; 2) "... tô detonado ..."; 3) "... tô reado, titia ..." e 4) ... Vige M aria, tô cum malestar da gota, visse?" também denotam exploração de enfermidade de forma abusiva, embora, não sob aspecto visual. Isto demonstra a intenção em induzir o usuário à situação de dependência do medicamento, além de aproveitar-se do estado de vulnerabilidade que acomete uma pessoa quando esta se encontra doente. $A$ busca desenfreada por lucrosnão justifica, porém, exacerbar esta condição.

A omissão da advertência obrigatória “Ao persistirem os sintomas o médico deve ser consultado" também ocorreu nas peças publicitárias de ambos os períodos ( $12,5 \%$ e 16,7\%). Esta advertência éuma exigência não só da RDC no 102/0010 eda RDC n 96/08 ${ }^{11}$ como também da Lei no 9.294/ $96^{24}$ para M IP. A justificativa para esta advertência se baseia no seguinte raciocínio: se o medicamento não for eficaz, não insista, procure um médico. A importância da advertência reside no fato de quea persistência da sintomatologia pode ser indício de grave problema de saúde, em quea intervenção do médico éimprescindível.

Observou-se que foram anunciados 2 medicamentos não registrados (um no 1 o período de captação e outro no 2ํ) o que se constitui em falta gravíssima, uma vez que comercializar medicamento não registrado se constitui em crime previsto no artigo 273 do Código Penal brasileiro.

A omissão de dados como contraindicações, reações adversas, cuidados/advertências e inte- 
rações medicamentosas seguida da ênfase a supostos benefícios demonstram a inten ção da indústria farmacêutica em atender a propósitos mercadológicos, uma vez que veicular informações sobre riscos possibilita o fortalecimento da capacidade deescolha da população, individual e coletivamente, podendo constituir-seem contrapropaganda do medicamento.

Segundo a Organização Mundial de Saúde, para que a automedicação ocorra de forma se gura e eficienteénecessário reconhecimento exato dos sintomas, estabelecimento dos objetivos terapêuticos, seleção do produto, determinação de dosagem e frequência de administração, le vando em conta histórico médico, contraindicações, doenças concomitantes, interação medicamentosa, monitoramento da resposta ao tratamento e possíveis efeitos adversos ${ }^{25}$.

A Tabela 4 demonstra a avaliação das informações que devem estar presentes nas propagandas de medicamentos, considerando suas peculiaridades farmacológicas em relação a outros produtos. Observa-seque, praticamente, não houve nenhum avanço na qualidade das propagandas veiculadas, pois as do 2o período também não apresentam as mesmasinformações que faltam àquelas do 10 .

Os argumentos mais utilizados na mensagem publicitária demedicamentos de ven da livre ressaltam, principalmente, eficácia, segurança, bem-estar, rapidez de ação, bom humor, energia, prazer e felicidade que eles trazem, minimizando ou simplesmente excluindo qualquer re ferência a riscos como possíveis interações medicamentosas, contraindicações e reações adversas, evitando-se determinar especificamente os grupos populacionais que não devem utilizá-los como idosos, crianças, diabéticos, hipertensos, demonstrando os riscos sanitários a queosusuários estão submetidos.

Por outro lado, o nome comercial e/ou a indicação terapêutica do medicamento foram veiculados em todas as peças publicitárias, de forma bastante enfática, seja através de exaustiva repetição dos mesmos, seja através de pluralidade de atribuições, afinal, são o cartão de visita do medicamento.

No entanto, os princípios ativos do medicamento não foram veiculados com a mesma intensidade. A omissão desteitem essencial em re lação à ênfase ao nome comercial sugere que este último éo diferencial na obtenção delucros, ainda mais se for levada em consideração a infinidade de medicamentos constituídos pelos mesmos princípios ativos.

Através da Análise de Conteúdo foi observado que a maioria dos elementos de convencimento/persuasão era indicativa de apelo ao consumo eindicação terapêutica (Tabela 5).

Nascimento e Sayd ao analisarem os termos mais utilizados em 100 peças publicitárias captadas, verificaram que as palavras emagrecer e/ou emagrecedor apareciam 40 vezes; dor, 28; gripe, 21; alivia e/ou alívio imediato, 19; saúde, 17; rápido e/ou rapidinho, 15; tosse, 15; problema, 15; azia, 15; melhor e/ou melhorar, 14; energia, 14; natural, 12; vitamina C, 11; passa e/ ou passar, 11; bom, 8; sintomas, 8; legal, 8; eficientee/ ou eficaz e/ ou eficácia, 8; saudável, 7 e má digestão, 7, reforçando 0 contexto constatado neste estudo $0^{15}$.

A produção de uma imagem adequada pre cisa apoiar-se na compreensão correta de dese jos, temores, preocupações e características fundamentais, em suma, da natureza dos humanos envolvidos em cada uma das esferas ${ }^{26}$. Seguindo esta linha de raciocínio, as propagandas analisa-

Tabela 4. Avaliação das informações inerentes ao medicamento nas propagandas captadas.

\begin{tabular}{|c|c|c|c|c|}
\hline \multirow{3}{*}{ I tens avaliados } & \multicolumn{4}{|c|}{ Presença nas peças publicitárias } \\
\hline & \multicolumn{2}{|c|}{ abril a setembro de 2008} & \multicolumn{2}{|c|}{ abril a setembro de 2010} \\
\hline & $\mathrm{N}$ & $\%$ & $\mathrm{~N}$ & $\%$ \\
\hline Indicação terapêutica & 8 & 100 & 5 & 8,3 \\
\hline Nome comercial & 8 & 100 & 6 & 100 \\
\hline Princípio ativo (DCB/DCI) & 0 & 0 & 0 & 0 \\
\hline Contraindicações & 0 & 0 & 0 & 0 \\
\hline Reações adversas & 0 & 0 & 0 & 0 \\
\hline Cuidados/advertências & 0 & 0 & 0 & 0 \\
\hline Interações medicamentosas & 0 & 0 & 0 & 0 \\
\hline
\end{tabular}


Tabela 5. Análise de conteúdo das mensagens publicitárias nas propagandas captadas.

\begin{tabular}{|c|c|c|c|c|}
\hline \multirow{3}{*}{ Categorias } & \multicolumn{4}{|c|}{ Frequência de veiculação } \\
\hline & \multicolumn{2}{|c|}{ abril a setembro de 2008} & \multicolumn{2}{|c|}{ abril a setembro de 2010} \\
\hline & $\mathrm{N}$ & $\%$ & $\mathrm{~N}$ & $\%$ \\
\hline Aspectos negativos & 0 & 0 & 0 & 0 \\
\hline Natural & 0 & 0 & 1 & 1,7 \\
\hline Alegria & 3 & 3,4 & 0 & 0 \\
\hline Acesso & 0 & 0 & 3 & 5 \\
\hline Exploração abusiva de enfermidade & 18 & 20,4 & 4 & 6,7 \\
\hline Eficiência/eficácia & 19 & 21,6 & 10 & 16,7 \\
\hline Indicação terapêutica & 21 & 23,9 & 24 & 40 \\
\hline Apelo ao consumo & 27 & 30,7 & 18 & 30 \\
\hline Total & 88 & 100 & 60 & 100 \\
\hline
\end{tabular}

das demonstraram claramente esta intenção através de expressões como: 1) "Pra você ficar legal, tome D!"; 2) "A alivia os primeiros sintomas para você continuar o seu dia-a-dia numa boa"; 3) "A marca I é sua garantia de qualidade!"; 4) "Viu? O Brasil intei ro está falando, é gripe, B!".

Estudos farmacológicos demonstram que se medicalizam cada vez mais fenômenos ligados à vida cotidiana e não à prevalência de alguma doença como estímulo à utilização de polivitamínicos como substitutos de dieta adequada, a qual não é valorizada como fonte privilegiada de nutrientes; prescrição de hipnosedantes para tratar insônia e ansiedade em casos associados ao estresse gerado pelos hábitos de vida da sociedade moderna ou uso de medicamentos contra azia e má digestão como solução a excessos alimentares. Enquanto isto, quase dois bilhões de pessoas, ou seja, um terço da população do planeta, não tem acesso regular a medicamentos essenciai ${ }^{27}$.

Esses fatos foram confirmados neste estudo através das expressões: 1) "J todo dia é saúde e energia!"; 2) "K ..., excelente pra aliviar ... cansaço”.

Não será demasiado enfatizar o papel da mensagem publicitária, em suas diversas formas de expressão, contribuindo para reforçar a medicalização e ajudando sobremaneira a despolitizar a compreensão do processo saúde/doença e da sua determinação social ${ }^{28}$.

As pessoas passam a acreditar que a saúde provém do medicamento e o consideram o ponto central e indispensável no processo saúde/doença, ignorando os demais fatores sociais e políticos envolvidos.

A dor, um dos maiores desafios da medicina, remetea uma experiência essencial mentesubjetiva e, portanto, pessoal e intransferível. Como não pode ser mensurada de maneira objetiva, leva as pessoas, muitas vezes, a buscar medicamentos como forma de alívio a um sofrimento. Desta forma, não há dúvidas quanto aos altos investimentos no marketing da dor.

As mensagens publicitárias exploram o discurso apelativo da dor através da apresentação desta como vilã e o medicamento como salvador, o que pode ser evidenciado nas expressões extraídas das peças analisadas como: 1) "Q uando você está com dor de cabeça qualquer barulhinho vira um barulhão, $\mathrm{H}$ age rapidinho no foco da dor e você só vai ouvir sininhos ao invés de barulhões"; 2) "Tomou H, a dor sumiu!"; 3) "Contra dor, febre egripe, com D, vocêvai ficar legal!"; 4) "Caiu, bateu, doeu, passa $\mathrm{G}$, que passa!".

A mensagem publicitária utiliza sloganscomo valiosos instrumentos de persuasão, os quais muitas vezes dizem muito mais que um simples nome da marca. Sendo assim, basta ouvi-los para que as pessoas saibam de que produto se trata. Neste estudo, foram identificados alguns como os seguintes: 1) "Tomou $\mathrm{H}$, a dor sumiu!"; 2) "Pra vocêficar legal, tomeD!"; 3) “É gripe, B!"; 4) "Passa G que passa!".

Os resultados das análises legal e de conteúdo demonstram a insuficiência do modelo atual de regulação da propaganda, dada a persistência do não cumprimento do estabelecido nas duas normas regulatórias aprovadas pela Anvisa ( $R D C$ № $102 / 00^{10}$ e RDC $n^{\circ} 96 / 08^{11}$ ), o que pode ser explicado pelo fato desta instituição de controle sanitário atuar após veiculação da peça publicitária. Entrea colocação do anúncio no mercado, a identificação da irregularidade ea tomada demedidas no âmbito do modelo regulatório, quando é o caso, transcorreperíodo detempo suficiente para 
que a ação reguladora se realize quando "o mal já está feito". Além disso, as multas efetivamente arrecadadas pela Anvisa, quando ocorrem as irre gularidades, têm valor irrisório frente ao total de gastos com propaganda realizados no setor e não há nada, no atual modelo regulatório, que impeça que os val ores relativos às multas sejam transferidos pela indústria para o preço dos medicamentos ${ }^{15}$.

\section{Conclusões}

Do ponto de vista legal, a análise demonstrou que todas as peças publicitárias avaliadas apresentaram al gum tipo deinfração, sendo em $100 \%$ das propagandas relacionadas a omissão de contraindicação principal e DCB/DCl.

$A$ análise de conteúdo demonstrou que a maioria dos elementos de convencimento/persuasão era indicativa de apelo ao consumo eindicação terapêutica e em nenhumas das propagandas foi indicado algum aspecto negativo relacionado ao medicamento.

$\mathrm{N}$ ão obstante o aprimoramento da legislação e das estratégias de monitoração e fiscalização da propaganda terem tido um grande avan- ço nosúltimos anos, ainda resta um longo caminho a percorrer, pois o que se tem ainda não é suficiente para coibir os abusos praticados em detrimento da saúde pública, como pode ser demonstrado pelo fato de que, apesar da aprovação de nova norma específica para regulamentação da propaganda de medicamentos, observase que, de forma geral, as peças publicitárias veiculadas continuam a apresentar características de propaganda abusiva e/ou enganosa, sugerindo que 0 alto faturamento do mercado farmacêutico brasileiro justifica a continuação da infração à legislação vigente.

0 estudo aponta a necessi dade do tema propaganda de medicamentos ser tratado em contexto mais amplo, como questão de saúde pública, considerando-se o cenário histórico-social em que se desenvolveu e o papel da Anvisa de proteção da saúde da população através de seu poder depolícia.

Embora se considere que a responsabilidade por regulamentação e fiscalização da propaganda seja do Estado, esta deve ser compartilhada com indústria, meios decomunicação eagências de publicidade. Além disso, éimprescindível informar e conscientizar a população para que esta reivindique seus direitos diante de situações enganosas.

\section{Colaboradores}

AM Batista trabalhou no desenvolvimento da pesquisa e na redação do artigo e M CRD CarvaIho, na orientação e na correção do artigo. 


\section{Referências}

1. Interfarma. Associação da Indústria Farmacêutica e de Pesquisas. Indicadores. M ercado farmacêutico mundial. 2008 abr [acessado 2009 jul 17]. Disponível em: http://www.interfarma.org.br/indicadores2. htm

2. Instituto Brasileiro de Geografia e Estatística. Pesquisa Nacional por Amostra de Domicílios. Síntese de Indicadores. [acessado 2007 out 27]. Disponível em: http://www.ibge.gov.br/home/estatistica/populacao/ trabalhoerendimento/pnad2006/sintesepnad2006.pdf

3. Sistema Nacional de Informações Tóxico-Farmacológicas. [acessado 2009 fev 11]. Disponível em: http://www.fiocruz.br/sinitox_novo/media/tab05 brasil 2007.pdf

4. Garrafa V. Inclusão social no contexto político da bioética. Rev. Brasileira de Bioética 2005; 1(2):122132.

5. Fagundes MJD, Soares M GA, Diniz NM, Pires JR, Garrafa V. Análise bioética da propaganda e publicidade de medicamentos. Cien Saude Colet 2007; 12(1):221-229.

6. Garrafa V. Da bioética de princípios a uma bioética interventiva. Bioética 2005; 13(1):124-134.

7. Batista AM, Campos M N, Freitas PCBDG, Araújo TS, Carvalho MCRD. Análise de peças publicitárias impressas de medicamentos na cidade de $\mathrm{N}$ atal (RN). Rev Téc Cient Farm Bioquím Anal Clín Toxicol 2007; 2(4):257-265.

8. Luchessi AD, Marçal BF, Araújo GF, Uliana LZ, Rocha MRG, PintoTJA. Monitoração de propaganda e publicidade de medicamentos: âmbito de São PauIo. Rev Bras Cienc Farm 2005; 41(3):345-349.

9. Heineck I, Gallina SM, Silva T, Pizzol FD, Schenkel EP. Análise da publicidade de medicamentos veiculada em emissoras de rádio do Rio Grande do Sul, Brasil. Cad Saude Publica 1998; 14(1):193-198.

10. Brasil. Resolução RDC $n=102$ de 30 de novembro de 2000. Aprova o regulamento sobre propagandas, mensagens publicitárias e promocionais e outras práticas cujo objeto seja a divulgação, promoção ou comercialização de medicamentos de produção nacional ou importados, quaisquer que sejam as formas e meios de sua veiculação, incluindo as transmitidas no decorrer da programação normal das emissoras de rádio e televisão. Diário Oficial da União 2000; 01 dez.

11. Brasil. Resolução RDC no 96 de 17 de dezembro de 2008. Aprova o regulamento sobre propaganda, publicidade, informação e outras práticas cujo objetivo seja a divulgação ou promoção comercial de medicamentos de produção nacional ou estrangei$\mathrm{ra}$, quaisquer que sejam as formas e meios de sua veiculação, incluindo as transmitidas no decorrer da programação normal das emissoras de rádio e televisão. Diário Oficial da União 2008; 18 dez.

12. Bardin L. Análise de conteúdo. Lisboa: Edições 70, LDA; 2000.

13. Pereira $O A$. Dicionário de substâncias farmacêuticas comerciais. 3a Edição. Rio de Janeiro: ABIQUIF; 2007.
14. Montes PR, Lopes AS, Silva ET, Ataídes Neto JC, Freitas JS, Araújo M P, Lobo LM C, Tresvenzol LFM, Prudente LR, Lima DM , Aquino AT, Zampieri ALTC. Propaganda e publicidade de medicamentos no estado de Goiás: análise das principais classes farmacológicas e infrações detectadas. Rev. Eletrônica de Farmácia 2005; 2(Supl. 2):119-121.

15. Nascimento AC, Sayd JD. "Ao persistirem os sintomas, o médico deverá ser consultado". Isto é Regulação? Physis 2005; 15(2):305-328.

16. França $\mathrm{AL}$. Dores garantem US\$ 1,2 bilhão para a indústria farmacêutica. [acessado 2009 fev 08]. 2008 Disponível em: http://www.febrafarma.org.br/index. php?area $=c 0 \&$ secao $=\&$ modul $0=$ clipping $\& i d=8598$

17. Intercontinental Marketing Services Company Information. 2003-2006 [acessado 2009 fev 08]. Disponível em: http://www.imshealth.com

18. Vilarino JF, Soares IC, Silveira CM, Rodel APP, Bortoli R, Lemos RR. Perfil da Automedicação em município do sul do Brasil. Rev Saude Publica 1998; 32(1):43-49.

19. Costa TCTD, Kerber LM, Volpato NM, Cauduro A, M achado Júnior HN, Pasa TBC, Senna JPM, Vianna RMJ, Schenkel EP. Comercialização de medicamentos em bares/lancheiras e armazéns/fruteiras em Porto Alegre. Ciênc Cult 1988; 40(3):285-288.

20. Tierling VL, Paulino MA, Fernandes LC, Shenkel $E P, M$ engue SS. Nível de conhecimento sobre a composição de analgésicos com ácido acetilsalicílico. Rev Saude Publica 2004; 38(2):223-227.

21. W zorek LF, Correr CJ, Trindade ACB, Pontarolo R. Analysis of medicine advertisement produced in Brazil. Pharmacy Practice 2007; 5(3):105-108.

22. Brasil. Portaria no $3.916 / \mathrm{GM}$ de 30 de outubro de 1998. Aprova a Política Nacional de Medicamentos. Diário O ficial da União 1998; 10 nov.

23. Sweetman SC. Martindale: the complete drug reference. $34^{\text {th }}$ Edition. London, Chicago: Pharmaceutical Press; 2005

24. Brasil. Lei no 9.294 de 15 de julho de 1996. Dispõe sobre as restrições ao uso e à propaganda de produtos fumígeros, bebidas alcoólicas, medicamentos, terapias e defensivos agrícolas, nos termos do $\S$ $4^{\circ}$ do art. 220 da Constituição Federal. Diário Oficial da União 1996; 16 jul.

25. World Health Organization (WHO). Guidelines for the regulatory assessment of medicinal products for use in self-medication. Geneva: WH O; 2000.

26. Gomes W. Transformações da política na era de comunicação de massa. São Paulo: Paulus; 2004.

27. World Health Organization (WHO). M edicines strategy: countries at the core. Geneva: WH O; 20042007.

28. Temporão JG. A propaganda de medicamentos e 0 mito da saúde. Rio de Janeiro: Graal; 1986.

Artigo apresentado em 10/04/2011

Aprovado em 01/08/2011

Versão final aprovada em 14/09/2011 